\title{
Is psychiatric residential facility discharge possible and predictable? A multivariate analytical approach applied to a prospective study in Italy
}

\author{
G. de Girolamo - V. Candini - C. Buizza - C. Ferrari - M. E. Boero • \\ G. M. Giobbio $\cdot$ N. Goldschmidt $\cdot$ S. Greppo $\cdot$ L. Iozzino $\cdot$ P. Maggi $\cdot$ \\ A. Melegari $\cdot$ P. Pasqualetti $\cdot$ G. Rossi
}

Received: 27 November 2012/ Accepted: 1 May 2013

(C) Springer-Verlag Berlin Heidelberg 2013

\begin{abstract}
Background A growing number of severely ill patients require long-term care in non-hospital residential facilities (RFs). Despite the magnitude of this development, longitudinal studies surveying fairly large resident samples and yielding important information on this population have been very few.

Aims The aims of the study were (1) to describe the socio-demographic, clinical, and treatment-related characteristics of RF patients during an index period in 2010; (2) to identify predictors and characteristics associated with discharge at the 1-year follow-up; (3) to evaluate clinicians' predictions about each patient's likelihood of home discharge (HD).

Methods A prospective observational cohort study was conducted involving all patients staying in 23 mediumlong-term RFs of the St John of God Order with a primary
\end{abstract}

The Perdove Group includes the following collaborators:

S. Andreose, P. Basso, R. Beneduce, F. Bongiorno, V. Braida,

E. Cortini, J. Dagani, F. De Dominicis, S. Donno, A. Di Giovanni,

A. Ghilardi, A. Jaretti Sodano, L. Magni, D. Milazzo, E. Lo Presti,

L. Paulon, R. Pioli, C. Ricci, L. Rillosi, G. Savio, L. Scaratti,

R. Scioli, I. Simonelli, L. Veneroni, S. Zamburlini, L. Zorzella.

Registered with ClinicalTrials.gov; identifier no. NCT01701765.

G. de Girolamo $(\bowtie) \cdot$ V. Candini · C. Buizza · C. Ferrari .

L. Iozzino · G. Rossi

IRCCS St John of God Fatebenefratelli, Via Pilastroni, 4, 25125

Brescia, Italy

e-mail: gdegirolamo@fatebenefratelli.it

C. Buizza

Department of Clinic and Experimental Sciences,

University of Brescia, Brescia, Italy

M. E. Boero - A. Melegari

Hospital Beata Vergine della Consolata, Turin, Italy psychiatric diagnosis. A comprehensive set of sociodemographic, clinical, and treatment-related information was gathered and standardized assessments (BPRS, HONOS, PSP, PHI, SLOF, RBANS) were administered to each participant. Logistic regression analyses were run to identify independent discharge predictors.

Results The study involved 403 patients (66.7\% male), with a mean age of 49 years $(S D=10)$. The participants' average illness duration was 23 years; median value for length of stay in the RF was 2.2 years. The most frequent diagnosis was schizophrenia $(67.5 \%) .104(25.8 \%)$ were discharged: $13.6 \%$ to home, $8.2 \%$ to other RFs, $2.2 \%$ to supported housing, and $1.5 \%$ to prison. Clinicians' predictions about HD were generally erroneous.

Conclusions Very few patients were discharged to independent accommodations after 1 year. The main variables associated with a higher HD likelihood were: illness duration of $<15$ years and effective social support during the previous year. Lower severity of psychopathology and higher working skill levels were also associated with a significantly greater HD likelihood.

Keywords Residential facility · Schizophrenia ·

Follow-up study · Outcome

G. M. Giobbio · P. Maggi

Hospital Sacro Cuore di Gesù, Milan, Italy

G. M. Giobbio · N. Goldschmidt · S. Greppo

Hospital Villa Sant'Ambrogio, Milan, Italy

P. Pasqualetti

Medical Statistics and Information Technology, Fatebenefratelli

Association for Research, Isola Tiberina, Rome, Italy 


\section{Introduction}

Despite the diffusion of community-based mental health services and more effective biological and psychosocial treatments, a substantial proportion of severely ill patients requiring long-term care tend to accumulate in non-hospital residential facilities (RFs) [1, 2]. Notwithstanding the magnitude of this development, many studies have investigated small samples of residents and used a cross-sectional design [3-5]. Only a few longitudinal studies have yielded important information about this population, consistently indicating the difficulties involved in discharging and placing these patients in independent accommodations [6-12].

\section{The Italian system of residential care}

In Italy, all mental hospitals (MHs) have been shut down, as required by the Law 180 passed in 1978; comprehensive information concerning the architecture and functioning of the mental health system in Italy can be found elsewhere $[13,14]$. Patients who require long-term residential care are now catered for by RFs. Detailed information about the quantity and quality of these facilities has been obtained through a nationwide survey of all RFs (the PROGRES study) conducted in 2000-2002 [15-19]. On 31 May 2000, there were $1,370 \mathrm{RFs}$ with 17,138 beds, an average of 12.5 beds each and a rate of 2.98 beds per 10,000 inhabitants. Residential provision varied tenfold between regions and discharge rates were very low: during 1999, more than a third of all RFs $(37.7 \%)$ had not discharged any patients and $31.5 \%$ had discharged only one or two. Most had $24 \mathrm{~h}$ staffing with 1.42 patients per full-time worker; RFs had different internal rules, and also links with local social services was variable between different facilities and areas. Compulsory stay is not permitted, although most facilities have some restrictive rules for their daily functioning. All these facilities are functionally linked to the departments of mental health (DMHs) functioning in the same catchment area, and generally host patients from the same area or neighbouring areas.

The second stage of this survey assessed in depth a representative sample of $\sim 20 \%$ of all residents $(N=2,962)$ staying in $265 \mathrm{RFs}$ in 2002 [20]. It was also possible to carry out a detailed cost evaluation and it was ascertained that each patient staying in RF had a cost between 7,851 and 34,650 US\$ per year; these costs are covered by the NHS, although most patients contribute with a percentage of their income (generally a pension). Unfortunately, the cross-sectional design of the PROGRES study did not allow for a longitudinal view of these patients.
The PERDOVE study (Progetto Epidemiologico Residenze Dimissione Ospiti e Valutazione Esiti-Epidemiological Project on Discharge from Residential Facilities and Outcome Assessment) is the first study in Italy aimed at obtaining comprehensive data on the course and outcome of RF patients and to verify whether discharge to independent accommodations is a real option for many patients. The present paper examined patients' characteristics and their 1-year outcomes, with three major aims: (1) to describe the socio-demographic, clinical, and treatmentrelated characteristics of RF patients during an index period in 2010; (2) to identify discharge-associated predictors and characteristics at 1-year follow-up; and (3) to evaluate clinicians' predictions as to each patient's likelihood of home discharge (HD). The primary end point was HD within 1 year as a measure of good outcome. We hypothesized that HD likelihood would be associated with both degree of social support external to facilities and degree of patient psychological and social impairment. Based on the PROGRES results (this study was carried out in 2002), we also hypothesized that HD rate would have been lower than $20 \%$ of the overall sample.

\section{Methods}

Study design

This is a prospective observational cohort study involving all St John of God Order's 23 medium-long-term RFs located in Northern Italy: all these RFs do not have any fixed-term time limit to patients' stay, and residents may stay even for years if necessary.

\section{Facility assessment}

We firstly used a structure schedule to assess the RFs in the following areas: logistics structure (i.e. building and structural features, accessibility, and urban transport); general organization (internal rules, meals, clothing, and personal hygiene); staff and user characteristics; staff and user (patients and families) meetings; documentation system; evaluation activities; and RF-provided rehabilitative activities.

\section{Patient recruitment and assessment}

All patients staying in the St John of God Order's 23 RFs in September 2010 with a primary psychiatric diagnosis and aged between 18 and 64 years were recruited. Exclusion criteria were age 65 years or older (elderly patients in Italy have access to psychogeriatric facilities, examined in a separate study), and primary diagnosis of organic mental 
disorder (i.e. dementia or mental retardation). The study was approved by the local research ethics committee and all participants provided written informed consent prior to evaluation.

A research assistant, together with the treating clinicians and staff, conducted a standardized assessment for each resident; treating clinicians made clinical diagnoses.

The Brief Psychiatric Rating Scale (BPRS) was used to assess psychopathology [21]. The Health of Nation Outcome Scale (HONOS) [22] and the Personal and Social Performance (PSP) scale, a modified version of the DSMIV Social and Occupational Functioning Assessment Scale (SOFAS), were used to assess psychopathology and social functioning [23]. The Specific Levels of Functioning (SLOF), recently considered the 'gold standard' in this field [24], was administered to assess psychosocial functioning and disability. Cognitive functioning was assessed with the Repeatable Battery for the Assessment of Neuropsychological Status (RBANS) [25]. The Physical Health Index (PHI) was used to measure the patients' physical health status [7].

As in the British Residential Study [26] and in the PROGRES survey [20], the treating psychiatrists' clinical predictive ability was evaluated by asking them to predict each patient's placement after 1 year. To evaluate the prediction of clinicians, we used two questions: 'Where do you anticipate that the patient will be in 12 months' time?', with six response options; the second question was 'What do you think prevents the patient's discharge within 1 year?'. The clinician was also asked to provide his/her opinion as to what might facilitate the patient's discharge within 1 year.

\section{One-year follow-up}

At the 1-year follow-up, the patients' clinical and life condition changes were evaluated and selected rating scales (e.g. HONOS, SLOF, BPRS, and PSP) were readministered. Research assistants contacted community psychiatrists for HD patients, and RF psychiatrists for RFtransfer patients, and asked them to fill out the follow-up documentation.

\section{Statistical analysis}

Descriptive statistics (percentages, standard deviation, means) for the patients' main socio-demographic, clinical, and treatment-related characteristics were computed. Fisher's exact tests and $\chi^{2}$ tests of association were used to assess differences in categorical variables between HD patients and stayers (all patients remaining in the same RF or transferred to other RFs/institutions [e.g. nursing homes, jail] at follow-up). Analysis of variance (ANOVA) and independent $t$ tests were used to compare HD patients and stayers for continuous variables.

A multiple correspondence analysis (MCA) was run to analyse the association between discharge status and score changes on selected assessment scales (e.g. BPRS, PSP, HONOS, and SLOF) at the 1-year follow-up. The assessment scale ratings were therefore re-codified into "low", "moderate", and "severe" categories according to internationally agreed scoring cutoffs of each scale (BPRS total score: low $[<72]$, moderate [73-95], severe [ $>96]$; PSP total score: low $[>72]$, moderate [41-71], severe $[<40]$; HONOS total score: low $[<12]$, moderate [13-24], severe [ $>25]$; SLOF mean score: low [ $>4]$, moderate $[3,4]$, severe $[<2]$ ). Category change over time (baseline to follow-up) was then codified as 'improved' ("i"), 'worsened' ("w"), or 'unchanged' ("u") in terms of psychopathology and functional impairment. We have also geometrically represented these three categories in a two-dimensional graph [27], in which the proximity (measured by Euclidean distance) between different variables points to their associations.

Lastly, logistic regression models were run to examine the probabilistic relationship between discharge and selected socio-demographic, clinical, and treatment-related variables, and assessment scales. The forward likelihood ratio covariate entry method was used to obtain HD predictors. Statistical analyses were conducted using SPSS version 13.0 and Language and Environment package R [28].

\section{Results}

Facility characteristics and restrictiveness

A total of 23 RFs participated in the study. Most RFs were independent buildings located in suburban areas, with a mean number of 17.5 residents per facility (range 5-29). The RF sample included a total of 22 clinicians, and $80 \%$ had $24 \mathrm{~h}$ staff rotation.

Eighty-five per cent of the RFs had an admissions waiting list averaging 11 weeks $(\mathrm{SD}=6.3)$. Standardized assessment instruments were used routinely in most facilities $(75 \%)$. Various types of rehabilitative activities were available: social skills training in $80 \%$ of facilities; individual and group psychoeducation in $65 \%$; job training in $65 \%$; and expressive/manual activities in all RFs. All RFs had restrictive rules concerning patients' daily life and behaviour. In $65 \%$ of RFs, the staff managed patients' and visitors' daily entry/exit times and details. In $85 \%$ of RFs, residents were allowed to come and go autonomously; in $40 \%$, patients who were allowed to exit had to specify their destination. 
In $40 \%$ of RFs, all patients were allowed to manage this own money, while for $55 \%$ this was only for the case of selected patients. Patients in $40 \%$ of the RFs had fixed bedtimes, generally consisting in the light-off of the night rooms, and also involving the closure of the entrance doors; in $50 \%$ of the RFs patients were allowed to refuse planned activity participation, while in $40 \%$, they were allowed to do so only occasionally.

The sample's socio-demographic characteristics

A total of 403 patients met the study entry criteria and were assessed at baseline. Table 1 shows the sample's main socio-demographic and clinical characteristics; missing data were few and never exceeded $8 \%$. The patients' mean age was 48 years $(\mathrm{SD}=10$; range $19-64$ ) and $2 / 3$ were male. Regarding socioeconomic status, the patients' average monthly income (before tax) was $€ 541$ (SD $=608$, median 260, range 0-6, 2,000). Economic strain indicators were common, although 190 patients $(47.7 \%)$ owned their home.

\section{Sample's clinical characteristics}

In terms of clinical characteristics, approximately two-third of the sample had a schizophrenia spectrum diagnosis; $42.3 \%$ of the residents had a secondary diagnosis of alcohol or substance abuse (in most cases a past lifetime diagnosis). Only a few patients had abused alcohol $(1.7 \%)$ or other substances $(0.7 \%)$ over the previous 6 months, and daily alcohol drinking was reported for $6.7 \%$ of the residents.

Mean age at first mental health service contact was 26.7 years $(\mathrm{SD}=10.7)$, with a mean illness duration of 23.1 years $(\mathrm{SD}=11.3)$. Approximately, one-third of the sample had a lifetime history of antisocial behaviour: 75 patients $(18.6 \%)$ had committed interpersonal violence. Nevertheless, during the year prior to study entry, the frequency of antisocial behaviour had been rather low: $3.1 \%(N=12)$ slapping, $1.3 \%(N=5)$ punching, $0.3 \%$ $(N=1)$ weapon use, and $2.3 \%(N=9)$ inappropriate sexual behaviours. A high proportion of patients $(41.9 \%$, $N=169$ ) had a history of self-harm and suicidal behaviour.

The PHI, assessing physical morbidity, showed that the most common physical problems were endocrine-metabolic and infective (including HIV+) of moderate or severe degree, affecting 7.2 and $7.5 \%$ of the sample, respectively. Other physical problems were less frequent and did not exceed $6 \%$ of the sample.
Table 1 The sample's socio-demographic and clinical characteristics $(N=403)$

\begin{tabular}{|c|c|c|}
\hline & $N$ & $\%$ \\
\hline \multicolumn{3}{|l|}{ Age groups (years) } \\
\hline $18-35$ & 43 & 10.8 \\
\hline $36-45$ & 94 & 23.6 \\
\hline $46-55$ & 154 & 38.7 \\
\hline $56-64$ & 107 & 26.9 \\
\hline \multicolumn{3}{|l|}{ Civil status } \\
\hline Never married & 285 & 70.7 \\
\hline Separated/divorced/widowed & 81 & 20.1 \\
\hline Currently married or cohabiting & 37 & 9.2 \\
\hline \multicolumn{3}{|l|}{ Occupational status } \\
\hline Disability pension & 308 & 77.2 \\
\hline Unemployed or supported employment & 78 & 19.5 \\
\hline Full or part-time ordinary work & 7 & 1.8 \\
\hline Other (housewife, student, etc.) & 6 & 1.5 \\
\hline \multicolumn{3}{|l|}{ Best occupational status ever achieved } \\
\hline Unskilled worker & 219 & 55.9 \\
\hline Skilled worker & 162 & 40.6 \\
\hline Professional & 19 & 4.8 \\
\hline \multicolumn{3}{|l|}{ Former place of residence } \\
\hline Home & 99 & 24.6 \\
\hline Other RF & 159 & 39.5 \\
\hline General hospital psychiatric ward & 88 & 21.8 \\
\hline Forensic mental hospital & 47 & 11.7 \\
\hline Other (e.g. prison, homeless, general hospital, etc.) & 6 & 1.5 \\
\hline \multicolumn{3}{|l|}{ Primary diagnosis } \\
\hline Schizophrenic disorders & 272 & 67.5 \\
\hline Personality disorders & 72 & 17.9 \\
\hline Other disorders & 59 & 14.6 \\
\hline \multicolumn{3}{|l|}{ Illness duration (years) } \\
\hline $1-10$ & 72 & 18 \\
\hline $11-15$ & 44 & 11 \\
\hline$\geq 16$ & 283 & 70.9 \\
\hline \multicolumn{3}{|l|}{ Age of first contact with mental health services (years) } \\
\hline$\leq 18$ & 96 & 24.6 \\
\hline $19-29$ & 159 & 40.7 \\
\hline$\geq 30$ & 136 & 34.8 \\
\hline \multicolumn{3}{|l|}{ Length of RF stay (years) } \\
\hline$\leq 3$ & 245 & 60.8 \\
\hline $3-6$ & 76 & 18.9 \\
\hline$>6$ & 80 & 19.8 \\
\hline \multicolumn{3}{|l|}{ Social support in the last year } \\
\hline Available and effective & 124 & 30.8 \\
\hline Available but ineffective & 144 & 35.7 \\
\hline Potentially available but difficult to mobilize & 61 & 15.1 \\
\hline Absent & 72 & 17.9 \\
\hline
\end{tabular}


At baseline $358(88.8 \%)$ patients were on psychotropic medication, $11(2.7 \%)$ not taking drugs, and for $34(8.4 \%)$ these data were missing. Three hundred and forty $(84.4 \%)$ patients were receiving at least one antipsychotic drug, 174 (43.2\%) benzodiazepines and $75(18.6 \%)$ antidepressants.

Daily activities and care characteristics

Regarding daily activities, $34.3 \%$ spent time with other patients, while $30.8 \%$ of the residents spent most of their time alone, uninvolved in any activity; approximately, onethird of the patients did nothing for more than $6 \mathrm{~h} /$ day. Nearly $29 \%$ of the sample did not participate in facility management; a minority did a variety of domestic or administrative chores (e.g. cooking, laundry or cleaning, gardening, etc.). Moreover, $58 \%$ of patients appeared motivated and collaborative with the treatment plan.

The mean RF stay duration was 4.2 years $(\mathrm{SD}=5.5$, median $=2.2$ ). Somewhat less than half of the sample $(44.2 \%)$ had spent more than 5 years in an inpatient psychiatric facility (including RFs or GHPUs), and a similar percentage $(46.4 \%)$ had been compulsorily admitted at least once. Treating clinicians predicted a high percentage of patients $(42.4 \%)$ to remain in their current RF in the following year; only for a minority $(16.1 \%)$ they predicted the move to independent accommodation or a life with their own family. Clinicians also reported psychopathology severity as the main obstacle to patient discharge (52.9\%), citing other problems for the remaining residents.

Standardized assessment scores for the all sample

At entry, the mean total BPRS score for 403 residents was 57.6 ( $\mathrm{SD}=17.4)$, thereby indicating a moderate symptom level. The HONOS mean total score, assessing clinical and social functioning, was also only moderate (18.8, SD = 7.9), whereas the PSP score (40.3, $\mathrm{SD}=14.1)$ showed significant psychosocial functioning impairment.

The SLOF rating's most affected area was "work ability" (mean score: $2.6, \mathrm{SD}=1.5$ ), followed by "interpersonal relations" (mean score: $3.3, \mathrm{SD}=1.3$ ). Lastly, the mean total RBANS (neuropsychological status) score was 70.7 (SD = 11.9), thereby indicating mild cognitive impairment.

HD-stayer differences at baseline

At the 1-year follow-up, $104(25.8 \%)$ patients were discharged: 55 home discharged, 33 to other RFs, 9 to supported housing, and 6 to prison. Fourteen patients refused the follow-up interview and 2 were lost to follow-up. Ten patients died before the 1-year follow-up assessment (one due to suicide).
Table 2 Significant home discharged-stayer differences in clinical and care characteristics comparison at baseline

\begin{tabular}{|c|c|c|c|c|}
\hline & $\begin{array}{l}\text { Home discharged } \\
(N=55)\end{array}$ & $\begin{array}{l}\text { Stayers } \\
(N=338)\end{array}$ & Test & $p$ value \\
\hline \multicolumn{5}{|l|}{ Primary diagnosis } \\
\hline Schizophrenic disorders & $23(41.8 \%)$ & $242(76.6 \%)$ & \multirow[t]{3}{*}{$\chi_{2}^{2}=26.53$} & \multirow[t]{3}{*}{$<0.0001$} \\
\hline Personality disorders & $17(30.9 \%)$ & $54(17.1 \%)$ & & \\
\hline Unipolar depression & $12(21.8 \%)$ & $20(6.3 \%)$ & & \\
\hline \multicolumn{5}{|l|}{ Mean of illness duration } \\
\hline Years & $16.3(\mathrm{SD}=11.5)$ & $23.9(\mathrm{SD}=10.9)$ & $F_{1}=22.86$ & $<0.0001$ \\
\hline \multicolumn{5}{|l|}{ Time spent doing nothing } \\
\hline$<6$ h/day & $42(76.4 \%)$ & $202(59.9 \%)$ & \multirow[t]{2}{*}{$\chi_{1}^{2}=5.43$} & \multirow[t]{2}{*}{0.020} \\
\hline More than $6 \mathrm{~h}$ /day & $13(23.6 \%)$ & $135(40.1 \%)$ & & \\
\hline \multicolumn{5}{|l|}{ Length of RF stay (years) } \\
\hline Mean & $2.3(\mathrm{SD}=1.96)$ & $4.6(\mathrm{SD}=5.8)$ & $F_{1}=8.33$ & 0.004 \\
\hline \multicolumn{5}{|c|}{ Social support in the last year } \\
\hline Available and effective & $28(50.9 \%)$ & $93(27.7 \%)$ & \multirow[t]{2}{*}{$\chi_{1}^{2}=11.94$} & \multirow[t]{2}{*}{0.001} \\
\hline Ineffective or absent & $27(49.1 \%)$ & $243(72.3 \%)$ & & \\
\hline \multicolumn{5}{|c|}{ Able to cooperate in the last year } \\
\hline Adequate cooperation & $41(74.5 \%)$ & $189(56.1 \%)$ & \multirow[t]{2}{*}{$\chi_{1}^{2}=6.65$} & \multirow[t]{2}{*}{0.010} \\
\hline Poor cooperation & $14(25.5 \%)$ & $148(43.9 \%)$ & & \\
\hline \multicolumn{5}{|c|}{ Patient stay prediction for 12 months' time } \\
\hline In the same RF & $10(18.2 \%)$ & $156(44.6 \%)$ & \multirow[t]{3}{*}{$\chi_{2}^{2}=55.3$} & \multirow[t]{3}{*}{$<0.0001$} \\
\hline In another RF & $18(33.7 \%)$ & $144(42.9 \%)$ & & \\
\hline At home & $27(49.1 \%)$ & $36(10.7 \%)$ & & \\
\hline
\end{tabular}


Table 2 shows the only socio-demographic, clinical, and treatment-related characteristics with statistically significant differences at baseline between stayers and HD patients.

A higher percentage of HD patients, as compared to stayers, were currently married or cohabiting ( 20 vs. $9.8 \%$; $\chi_{1}^{2}=4.98, p=0.026$ ), and employed in a supported work (14.5 vs. $\left.5 \% ; \chi_{1}^{2}=7.15, p=0.014\right)$.

Selected socio-demographic (e.g. civil and occupational status), clinical (e.g. primary diagnosis, illness duration, and age of first contact with services), and psychosocial (e.g. inactivity, social support, and cooperation capacity in the last year) were the only variables differentiating HD patients from stayers at baseline. Concerning the appropriateness of current stay at an RF, clinicians judged RF stay as being appropriate for $94.5 \%$ of HD patients and for $74.8 \%$ of stayers $\left(\chi_{1}^{2}=10.61, p=0.001\right)$.

Assessment instrument mean score differences at baseline and follow-up

Table 3 shows the mean baseline scores for the BPRS, PSP, HONOS, and SLOF sub-scales for the two cohorts and whether there was any statistically significant difference at study entry. It also shows the 1-year follow-up scores and amplitude of score change (if any) over time. Only two statistically significant changes over time were observed: the HD cohort's BPRS and SLOF work skills sub-scale; all other scores showed no significant changes between the two time points.

An MCA was run to analyse the ways in which assessment score changes were associated with discharge status (Fig. 1). The HD category (OUTCOME_HD) appears close to the 'improved' categories, as expressed by the BPRS (BPRS_i), the HONOS (HONOS_i), and the SLOF work skill sub-scale (SLOFskill_i), and is represented by the marked circle. Conversely, the 'Stayer' category (OUTCOME_S) shows a strong association with the 'unchanged' (thin circle). A different performance, which was essentially unrelated to discharge outcome, was observed in patients reporting 'worsened' psychopathological and functional outcomes (categories in the upper circle). This unexpected effect was probably due to the latter category's limited frequency in the sample (patients with 'worsened' status represented, on average, $<9 \%$ of the sample for each assessment instrument, whereas the 'improved' and 'unchanged' status represented about 35 and $55 \%$ of the sample, respectively).

Variables associated with discharge prediction

Table 4 shows the three logistic regression models' results, which identify HD predictors. Odds ratios of being home discharged versus remaining in the same RF, transfer to other RF, or to other institutions (e.g. prison, nursing home) were calculated for each model. The first model included illness duration, occupational status, diagnosis, length of RF stay, social support in the previous year, and time spent "doing nothing". Three variables were associated with a higher HD probability: shorter illness duration, available social support in the last year, and a diagnosis of unipolar depression.

These last results were also confirmed by the third model where the differences in psychopathology and psychosocial functioning between baseline and the 1-year follow-up were analysed: scores on the BPRS and on the

Table 3 Selected assessment instrument score differences between home discharged patients and stayers

\begin{tabular}{|c|c|c|c|c|}
\hline & \multicolumn{2}{|l|}{ Baseline } & \multicolumn{2}{|l|}{ Follow-up } \\
\hline & $\begin{array}{l}\text { Home discharged } \\
\text { (mean, SD) } \\
(N=55)\end{array}$ & $\begin{array}{l}\text { Stayers } \\
(\text { mean, SD) } \\
(N=338)\end{array}$ & $\begin{array}{l}\text { Home discharged } \\
\text { (mean, SD) } \\
(N=55)\end{array}$ & $\begin{array}{l}\text { Stayers } \\
(\text { mean, SD) } \\
(N=338)\end{array}$ \\
\hline BPRS & $51.2^{*, \#}(14.1)$ & $58.7 *(18.8)$ & $45.7^{\wedge}, \#(15.7)$ & $57.4^{\wedge}(19.6)$ \\
\hline HONOS & $16.2 *(7.5)$ & $19.3^{*}(7.9)$ & $14.5^{\wedge}(8.9)$ & $18.8^{\wedge}(8.2)$ \\
\hline FPS & $45.6^{*}(14.8)$ & $39.5^{*}(13.7)$ & $48.8^{\wedge}(19.8)$ & $39.7^{\wedge}(14.9)$ \\
\hline \multicolumn{5}{|l|}{ SLOF } \\
\hline Interpersonal & $3.6 *(0.9)$ & $3.2 *(0.9)$ & $3.5^{\wedge}(1.2)$ & $3.3^{\wedge}(0.9)$ \\
\hline Acceptable behaviour & $4.5(0.5)$ & $4.4(0.6)$ & $4.6(0.4)$ & $4.4(0.6)$ \\
\hline Community activities & $4.0 *(0.9)$ & $3.4 *(1.2)$ & $3.9^{\wedge}(1.1)$ & $3.5^{\wedge}(1.1)$ \\
\hline Work skills & $3.1^{*}, \S(1.3)$ & $2.5^{*}(1.1)$ & $3.5^{\wedge}, \S(1.1)$ & $2.6^{\wedge}(1.1)$ \\
\hline
\end{tabular}

* Statistically significant differences $(p<0.01)$ between home discharged and stayers at the same point in time (baseline)

$\wedge$ Statistically significant differences $(p<0.01)$ between home discharged and stayers at the same point in time (follow-up)

\# Statistically significant differences $(p<0.01)$ between home discharged and stayers over time (from baseline to follow-up)

$\S$ Statistically significant differences $(p<0.05)$ between home discharged and stayers over time (from baseline to follow-up) 
Fig. 1 Changes in mean scores of BPRS, HONOS, FPS, and SLOF over time: results of the multiple correspondence analysis (MCA)

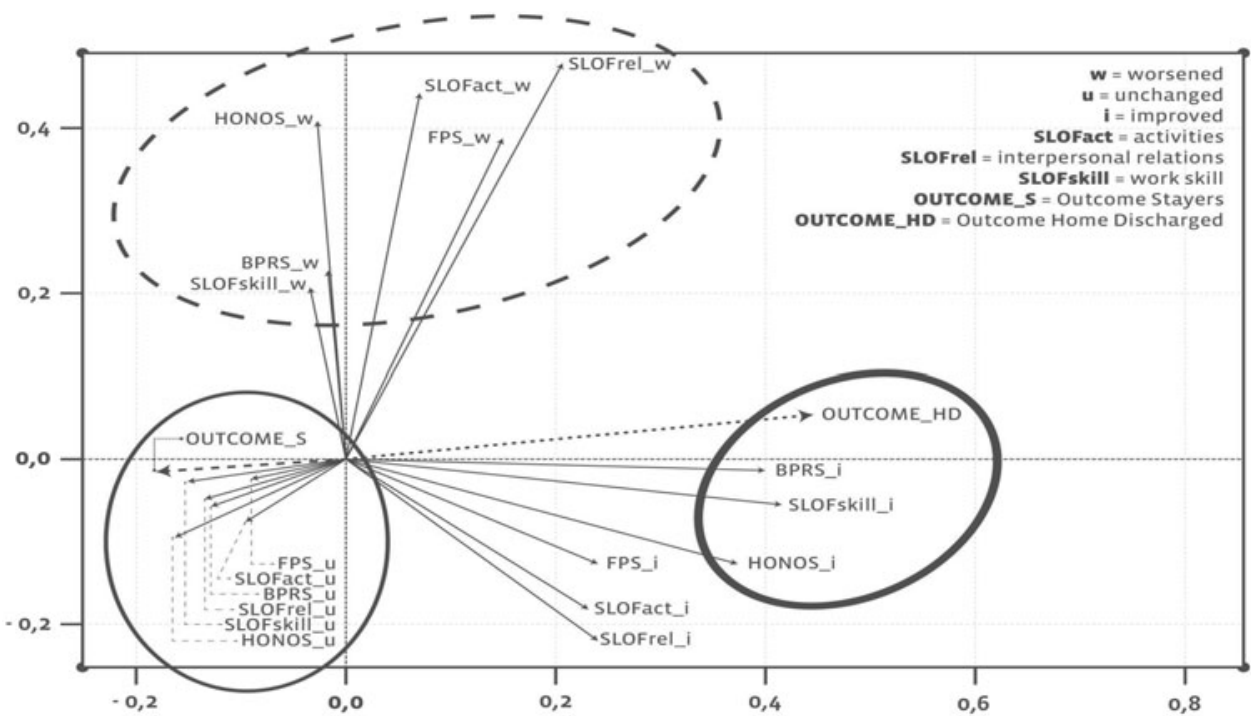

Table 4 Odds ratio (and $95 \%$ confidence intervals) for home discharge predictors

\begin{tabular}{lll}
\hline & OR & CI \\
\hline 1st Model & & \\
Illness duration (<15 vs. $>15$ years) & 2.7 & $1.4-5.2$ \\
Social support in the last year (available vs. unavailable) & 2.4 & $1.3-4.5$ \\
Diagnosis (schizophrenia vs. unipolar depression) & 0.2 & $0.09-0.61$ \\
2nd Model (psychopathology and psychosocial functioning at baseline) & & \\
BPRS (low vs. moderate) & 4.7 & $1.4-15.9$ \\
SLOF working skills (low vs. high) & 4.6 & $1.2-11.5$ \\
SLOF working skills (moderate vs. high) & 2.1 & $1.1-4.5$ \\
3rd Model (psychopathology and psychosocial functioning & & \\
differences between baseline and 1-year follow-up) & & $1.9-23.8$ \\
BPRS (improved vs. worsened) & 8.6 & $1.2-5.1$ \\
BPRS (unchanged vs. worsened) & 1.9 & $1.7-17.9$ \\
SLOF working skills (improved vs. worsened) & 6.3 & $1.2-4.9$ \\
SLOF working skills (unchanged vs. worsened) & 1.7 & \\
\hline
\end{tabular}

working skills SLOF sub-scale, showing improvement, were associated with a higher likelihood of HD. The variables diagnosis, BPRS score, illness duration, and social support were confirmed as predictors of HD also by considering a full (including all variables) logistic model.

\section{Clinicians' discharge predictions}

Clinicians showed a high erroneous prediction rate as to patients' HD probability. They predicted HD for 63 patients: at the end of the 1-year follow-up, 55 patients were actually HD. However, only 27 of the latter group $(49.0 \%)$ were among those for whom clinicians predicted HD: in other words, their original predictions included patients who were not among those actually discharged. The tetrachoric uncertainty correlation coefficient and the Cohen's Kappa were computed. These two indices yielded
0.1 for uncertainty and 0.4 for Kappa, respectively, indicating a low association and poor agreement between clinicians' discharge predictions and patients' actual discharge status at the 1-year follow-up.

\section{Discussion}

The PERDOVE project is the first comprehensive followup study conducted among long-term RF patients in Italy and one of the very few carried out internationally. We expected a low discharge rate to be associated with weak social support and poor psychosocial functioning. We also expected that clinicians would show rather good predictive ability as to patient placement after 1 year. Our results showed that long-term care was the most frequent outcome for participants, although some reasons for this limited 
patient turnover should be considered. Firstly, many patients who had been in MHs before their current RF stay may had lost their community ties. Secondly, alternative affordable accommodations for more independent patients may have been lacking. Lastly, their psychopathology, and especially daily living skill severity, made discharge to independent accommodation a very unlikely outcome. For some patients, RFs represent 'homes for life' [29], due to difficulty in progressing to a higher level of autonomy in independent settings.

Our study, however, yielded data that might help clinicians develop action plans based on the personalized assessment of patient discharge likelihood. Our findings may also serve in developing treatment algorithms to predict changes (or absence of change) in these patients. There is indeed a growing interest with respect to the construction of models designed to identify and assess the quality standards of mental health services [30, 31].

The resident population

Residents were predominantly middle aged, single men suffering from unremitting schizophrenic symptoms from early adulthood.

Half of the patients were 'new' long-stay patients, never admitted to obsolete psychiatric institutions, and this finding is in line with the results of the nationwide PROGRES survey. Patients had high levels of disability in psychosocial functioning and a moderate degree of cognitive impairment and symptom severity. Over time, acute symptoms decreased, whereas psychosocial functioning impairment persisted or worsened, especially in the area of work skills and interpersonal relationships.

\section{Residents' clinical features and activity levels}

Approximately, one-third of participants had a history of antisocial behaviour, although the rate of violent behaviours during the RF stay was low and limited to a small nucleus of patients. This result is consistent with data obtained elsewhere $[3,32,33]$. Residents did not have high physical morbidity and most general health needs appeared to be met. Physical limitations did not play a significant role in residents' inactivity.

The death rate was 2.48 (per thousand), about half as compared to the death rate of other Italian studies carried out among long-stay psychiatric patients [20, 34, 35]. In the 23 sampled facilities, one suicide occurred during the past year.

In terms of neuropsychological status assessment, the RBANS mean total score indicated the presence of a mild cognitive impairment and was strikingly similar to the RBANS mean score observed in 129 patients with schizophrenia assessed in the RBANS validation study
[25]. The RBANS mean total score showed no statistically significant HD-stayer differences. Data on cognitive functioning are clinically important and should be regularly collected, because it has been demonstrated that psychosocial functioning is more related to cognitive functioning than to symptom severity [36].

As observed in other surveys [8, 37], approximately one-third of patients did not participate in RF chores. In terms of institutional support/rehabilitation, most RF activities concerned facility management, and few were targeted at integrating patients within the local community. This limitation does not help patients develop their social skills, increasing the odds of prolonged institutionalization.

\section{Discharge predictors}

After 1 year, $25 \%$ of residents were discharged: only $14 \%$ of these, however, were HD (either alone or with family). These data are similar to those observed in other studies [10, 38-41]. Clinicians in the present study identified severity of psychopathology as being the main obstacle preventing patient discharge; the BPRS mean scores, however, did not point to a high level of psychiatric symptomatology. Thus, degree of psychosocial and functional impairment, as shown by assessment instrument mean scores and by a number of daily functioning indicators, was a strong stayer predictor. Interestingly, at baseline HD patients were considered to be appropriately placed in the RF at a higher frequency than stayers, meaning that at that time they did need a residential treatment and that in this subgroup of patients treatment did lead to a substantial improvement.

The main factor impeding discharge, however, was social support system unavailability. Only approximately one-third of patients had an effective social support system available (usually their families), which could also provide key assistance in case of discharge. Important enough, social support is a modifiable factor, whereas other variables associated with discharge are not (for instance, length of illness). Moreover, other studies [8] have found that social support for residents is a key variable in promoting patient autonomy, and residential programmes should do as much as they can to keep family ties as strong as possible, even in situations where cohabitation is not a viable option.

Who are home discharged patients?

HD patients are those with lower psychopathology and higher job skill levels. Indeed, the job skill improvement we observed may have also been due to the availability of specific job training programmes reported in $65 \%$ of the surveyed RFs. More importantly, only these two dimensions were sensitive to change after 1 year. When this 
change was positive, it was a strong HD predictor: patients improving in psychopathology had a nine times higher probability of being home discharged than that of worsened patients. Similarly, HD probability was six times greater in patients with improved job skills. These data are similar to Trieman and Leff's findings showing that $39 \%$ of patients leaving RFs were significantly more skilled than those not discharged [29, 32]. Moreover, in other studies the variables of "working skills" and lower degree of overall psychopathology were important home discharge predictors $[11,12,40]$.

Our own study's social functioning and psychopathology scale score trend showed that HD patients improved in many areas after 1 year. Similarly, in a 2-year follow-up study, HD patients improved in symptom patterns [42]. The non-discharged patients in the present study, conversely, showed no changes. This result is in line with other findings and suggests that selected patients, with a long history of illness, can improve during an RF stay and achieve discharge to the community $[9,11]$.

Other variables identifying HD patients were illness duration, social support, and type of diagnosis. The quantification of HD probability yielded by the logistic regression models allowed us to argue that the patients with a higher probability of HD were those with an illness duration of $<15$ years, who had received effective social support over the previous year and had a severe unipolar depression versus schizophrenia spectrum diagnosis. Even in Priebe's study [11], HD patients were less likely to have a diagnosis of schizophrenia than non-discharged patients.

Are clinicians able to actually predict patient discharge?

Treating clinicians had predicted that more than half of the sample $(57.6 \%)$ would have been discharged, after 1 year, to any destination (including other institutional accommodations), and that $16.1 \%$ would have been HD. Yet, the tetrachoric uncertainty correlation coefficient showed that the clinicians predicted HD for patients who were mostly not among those actually discharged. The clinical implication of this important finding is that clinicians working in RFs should employ the variables that have been shown to be strongly associated with discharge status, so as to more accurately finalize treatment plans, establish personalized rehabilitation programmes, and inform patients and their families of likely future developments.

A few recommendations to improve the quality of residential care

As a first point, the role of RFs should be clearly defined, that is whether they should be conceptualized as intensive treatment programmes, or merely as ordinary homes or living settings for patients with a long illness duration, marked impairment in cognitive and psychosocial functioning, and low or absent social support.

Related to this point, there is the need to develop a clear taxonomy of RFs, based on specific operational criteria. Since we have demonstrated once more that discharge from RFs is an unlikely option for most patients, efforts should be targeted at the creation of an environment which favours the best quality of life for residents. From this perspective, size represents a critical variable for any taxonomy of residential settings: small RFs help create a homely environment which is in huge contrast to the institutional, dehumanizing environments of the past: RFs should possibly never host $12-15$ patients. Finally, a small size of these facilities makes preserving patients' privacy possible, which is recognized as one of the priority needs for residents, and this has precise implications in terms of architectural features (e.g. availability of single rooms, private bathrooms, etc.) [43].

Finally, outcome research should refrain from generic questions (e.g. 'Does residential care work?') and should address specific questions, such as 'What kind of residential care appears to be most effective for what kinds of residents by what type of outcomes and in what kind of social and service context?'

\section{Limitations}

Some limitations must be considered when drawing inferences from the present data. Patients were not assessed via structured diagnostic interview: diagnostic reliability might therefore be limited. The risk of drawing inferences on misdiagnosed participants, however, can be considered relatively low, given that broad diagnostic categories were used and that diagnoses were made after a long period of close inpatient observation. A second limitation is that the care content and quality evaluation was not based on more sophisticated instruments investigating critical areas, such as patient needs [44] and content of care [45]; on the other hand, a survey of patients' service satisfaction, quality of life, and spirituality has been reported in another paper. Lastly, another limitation concerns the length of follow-up. In a sample of chronically mentally ill individuals, it is generally difficult to assess illness course and major changes in symptomatology and psychosocial functioning in just 1 year.

Acknowledgments The study was entirely supported by a grant from the Associazione Fatebenefratelli for Research (AFAR). We thank Fra Marco Fabello for his valuable support in the realization of this study. We are grateful to Lorenzo Burti and Antonello Preti for their helpful comments on the paper. 
Conflict of interest The authors have no conflict of interest regarding this paper.

\section{References}

1. Lamb R, Bachrach L (2001) Some perspectives on deinstitutionalization. Psychiatr Serv 52(8):1039-1045

2. Priebe S, Turner T (2003) Reinstitutionalisation in mental health care. BMJ 326(7382):175-176

3. Mowbray C, Greenfield A, Freddolino P (1992) An analysis of treatment services provided in group homes for adults labeled mentally ill. J Nerv Ment Dis 180(9):551-559

4. Rimmerman A, Schnee J, Klein I (1993) Individuals with psychiatric disabilities in adult homes: monitoring changes over time. Int J Rehabil Res 16(1):55-58

5. Donnelly M, McGilloway S, Mays N, Perry S, Lavery C (1997) A 3- to 6-years follow-up of former long-stay psychiatric patients in Northern Ireland. Soc Psychiatry Psychiatr Epidemiol 32(8): $451-458$

6. O'Discroll C (1991) The TAPS project: 7. Mental hospital closure- a literature review of outcome studies and evaluative techniques. Br J Psychiatry Suppl 19:7-17

7. O'Discroll C, Leff J (1993) The TAPS project: 8. Design of the research study on the long-stay patients. Br J Psychiatry Suppl 19:18-24

8. Segal SP, Kotler PL (1993) Sheltered care residence: ten-year personal outcomes. Am J Orthopsychiatry 63(1):80-91

9. Leff J, Trieman N, Kappa M (2000) The TAPS project. A report on 13 years research, 1985-1998. Psychiatr Bull R Coll Psychiatr 24(5): $165-168$

10. Räsänen S, Hakko H, Isohanni M, Nieminen P, Moring J (2000) Community placement of long-stay psychiatric patients in Northern Finland. Psychiatr Serv 51(3):383-385

11. Priebe S, Hoffmann K, Isermann M, Kaiser W (2002) Do longterm hospitalised patients benefit from discharge into the community? Soc Psychiatry Psychiatr Epidemiol 37(8):387-392

12. Anderson J, Dayson D, Wills W, Gooch C, Margolius O, O'Driscoll C, Leff J (1993) The TAPS project. 13: clinical and social outcomes of long-stay psychiatric patients after one year in the community. Br J Psychiatry Suppl 19:45-56

13. de Girolamo G, Cozza M (2000) The Italian psychiatric reform. A 20-year perspective. Int J Law Psychiatry 3-4:197-214

14. de Girolamo G, Barbato A, Bracco R, Gaddini A, Miglio R, Morosini P, Norcio B, Picardi A, Rossi E, Rucci P, Santone G, Dell'Acqua G, PROGRES-Acute group (2007) Characteristics and activities of acute psychiatric in-patient facilities: national survey in Italy. Br J Psychiatry 191:170-177

15. de Girolamo G, Picardi A, Micciolo R, Falloon I, Fioritti A, Morosini P, Italian PROGRES study group (2002) Residential care in Italy: a national survey of non-hospital facilities. Br J Psychiatry 81:220-225

16. Santone G, de Girolamo G, Falloon I, Fioritti A, Micciolo A, Picardi A, Zanalda E, PROGRES Group (2005) The process of care in residential facilities-a national survey in Italy. Soc Psychiatry Psychiatr Epidemiol 40(7):540-547

17. Tomasi R, de Girolamo G, Santone G, Picardi A, Micciolo R, Semisa D, Fava S, PROGRES Group (2006) The prescription of psychotropic drugs in psychiatric residential facilities: a national survey in Italy. Acta Psychiatr Scand 113(3):212-223

18. Rucci P, Picardi A, de Girolamo G, Santone G, Borsetti G, Morosini P, PROGRES group (2006) The quality of life of the mentally ill living in residential facilities: findings from a national survey in Italy. Eur Arch Psychiatry Clin Neurosci 256(6): $372-381$
19. Picardi A, de Girolamo G, Santone G, Falloon I, Fioritti A, Micciolo R, Morosini P, Zanalda E, PROGRES Group (2006) The environment and the staff of residential facilities data from the Italian 'progres' national survey. Community Ment Health J 42(3):263-791

20. de Girolamo G, Picardi A, Santone G, Falloon I, Morosini P, Fioritti A, Micciolo R, PROGRES Group (2005) The severely mentally ill in residential facilities: a national survey in Italy. Psychol Med 35(3):421-431

21. Ventura J, Green MF, Shaner A, Liberman RP (1993) Training and quality assurance with the brief psychiatric rating scale: the drift busters. Int J Methods Psychiatric Res 3(4):221-244

22. Wing JK, Beevor AS, Curtis RH (1998) Health of the Nation Outcome Scale (HoNOS). Research and development. Br J Psychiatry 174:432-434

23. Morosini PL, Magliano L, Brambilla L, Ugolini S, Pioli R (2000) Development, reliability and acceptability of a new version of the DSM-IV social and occupational functioning assessment scale (SOFAS) to assess routine social functioning. Acta Psychiatr Scand 101(4):323-329

24. Harvey P, Raykov T, Twamley E, Vella L, Heaton R, Patterson T (2011) Validating the measurement of real-world functional outcomes: phase I results of the VALERO study. Am J Psychiatry 168(11):1195-1201

25. Gold JM, Queern C, Iannone VN, Buchanan RW (1999) Repeatable battery for the assessment of neuropsychological status as a screening test in schizophrenia, I: sensitivity, reliability, and validity. Am J Psychiatry 156(12):1944-1950

26. Lelliott P, Audini B, Knapp M, Chisholm D (1996) The mental health residential care study: classification of facilities and description of residents. Br J Psychiatry 169(2):139-147

27. Greeacre MJ (1988) Correspondence analysis of multivariate categorical data by weighted least squares. Biometrika 75: 457-467

28. R Development Core Team (2011) R: a language and environment for statistical computing. R Foundation for Statistical Computing. doi:10.1007/978-3-540-74686-7

29. Trieman N, Smith HE, Kendal R, Leff J (1998) The TAPS Project 41: homes for life? Residential stability five years after hospital discharge. Community Ment Health J 34(4):407-417

30. Moran V, O'Connor S, Borowitz M (2013) International approaches to measuring the quality of mental health care. Epidemiol Psychiatr Sci. doi:10.1017/S2045796012000704

31. Ammadeo F, Tansella M (2012) Quality of mental health care indicators to improve care. Epidemiol Psychiatr Sci. doi: $10.1017 / \mathrm{S} 2045796012000698$

32. Trieman N, Leff L (2002) Long-term outcome of long-stay psychiatric in-patients considered unsuitable to live in the community. Br J Psychiatry 181:428-432

33. Flannery R, Fisher W, Walker A (2000) Characteristics of patient and staff victims of assaults in community residences by previously nonviolent psychiatric inpatients. Psychiatr Q 71(3):195203

34. Valenti M, Necozione S, Busellu G, Borrelli G, Lepore AR, Madonna R, Altobelli E, Mattei A, Torchio P, Corrao G, Di Orio F (1997) Mortality in psychiatric hospital patients: a cohort analysis of prognostic factors. Int J Epidemiol 26(6):1227-1235

35. D'Avanzo B, La Vecchia C, Negri E (2003) Mortality in longstay patients from psychiatric hospitals in Italy. Results from the Qualyop Project. Soc Psychiatry Psychiatr Epidemiol 38(7):385-389

36. Giugiario M, Crivelli B, Mingrone C, Montemagni C, Scalese M, Sigaudo M, Rocca G, Rocca P (2011) Cognitive function and competitive employment in schizophrenia: relative contribution of insight and psychopathology. Soc Psychiatry Psychiatr Epidemiol 47:553-561 
37. Preti A, Rucci P, Gigantesco A, Santone G, Picardi A, Miglio R, de Girolamo G, PROGRES-Acute Group (2009) Patterns of care in patients discharged from acute psychiatric inpatient facilities: a national survey in Italy. Soc Psychiatry Psychiatr Epidemiol 44(9):767-776

38. Killaspy H, Zis P (2012) Predictors of outcomes for users of mental health rehabilitation services: a 5-year retrospective cohort study in inner London, UK. Soc Psychiatry Psychiatr Epidemiol [Epub ahead of print]

39. D'Avanzo B, Barbato A, Barbui C, Battino RN, Civenti G, Frattura L (2003) Discharges of patients from public psychiatric hospitals in Italy between 1994 and 2000. Int J Soc Psychiatry 49(1):27-34

40. D'Avanzo B, Battino RN, Gallus S, Barbato A (2004) Factors predicting discharge of patients from community residential facilities: a longitudinal study from Italy. Aust N Z J Psychiatry 38(8):619-628
41. Leff J (1993) All the homeless people: where do they all come from? BMJ 306(6879):669-670

42. Hobbs C, Tennant C, Rosen A, Newtton L, Lapsley HM, Tribe K, Brown JE (2000) Deinstitutionalisation for long-term mental illness: a 2-year clinical evaluation. Aust $\mathrm{N} \mathrm{Z} \mathrm{J}$ Psychiatry 34(3):476-483

43. Timko C (1996) Physical characteristics of residential psychiatric and substance abuse programs: organizational determinants and patients outcomes. Am J Community Psychol 24(1):173-192

44. Slade M, Phelan M, Thornicroft G, Parkman S (1996) The Camberwell Assessment of Need (CAN): comparison of assessments by staff and patients of the needs of the severely mentally ill. Soc Psychiatry Psychiatr Epidemiol 31(3-4):109-113

45. de Jong A (2000) Development of the International Classification of Mental Health Care (ICMHC). Acta Psychiatr Scand Suppl 405:8-13 